\title{
Concepções de Homens Hospitalizados sobre a Relação entre Gênero e Saúde ${ }^{1}$
}

\author{
Florêncio Mariano da Costa-Júnior \\ Ana Cláudia Bortolozzi Maia ${ }^{2}$ \\ Universidade Estadual Paulista (UNESP)
}

\begin{abstract}
RESUMO - A saúde masculina é ainda pouco discutida. Estudos mostram que há um padrão social hegemônico sobre o masculino que influencia comportamentos preventivos de homens diante da saúde. Esta pesquisa, qualitativo-descritiva, investigou por meio da análise de conteúdo de entrevistas de dois homens hospitalizados, as suas concepções sobre gênero e saúde/adoecimento. Sob o ponto de vista masculino, homens e mulheres ficam doentes igualmente, embora as mulheres cuidem mais e preventivamente da sua saúde devido ao corpo reprodutivo. Os homens cuidam menos da saúde porque têm dificuldades em se afastar do trabalho, procuram por ajuda médica apenas diante de situações críticas que impõem limites na vida social e adoecem de modo mais severo. As concepções identificadas enfatizam a necessidade de elaboração de políticas públicas, que visem promover a saúde, específicas à população masculina.
\end{abstract}

Palavras-chave: masculinidade; gênero; hospitalização; pesquisa qualitativo-descritiva.

\section{Conceptions of Hospitalized Men about the Relation between Gender and Health}

\begin{abstract}
The masculine health is still little argued. Studies show that there is a hegemonic social standard on masculine that influences men's preventive behaviors on health. This study, qualitative-descriptive, had investigated by means of the interview analysis of two hospitalized men, their conceptions about the relation between gender, health/illness. Under the masculine point of view, men and women become equally ill, even though women take care more and preventively of their health due to her reproductive body. Men are careless of their health because they have difficulties in get out from work, they only look for medical aid in critical situations that limits their social life, and they get more severe diseases. The identified conceptions emphasize the necessity of elaboration of public policies to health's promotion, specific to the masculine population.
\end{abstract}

Keywords: masculinity, gender; hospitalization; qualitative-descriptive research.

O movimento feminista historicamente lutou pela equidade de direitos entre mulheres e homens. Uma das denúncias desse movimento se referia à insuficiência de serviços públicos destinados às mulheres (Teles, 1999). Nas últimas décadas, a disposição de serviços de saúde mudou significativamente e, atualmente, as esferas governamentais buscam disponibilizar uma assistência integral à saúde das mulheres (Figueiredo, 2005; Gomes \& Nascimento, 2006). No entanto, há pouca estruturação no atendimento e assistência à saúde quando se trata de demandas específicas do gênero masculino (Doyal, 2001; Figueiredo, 2005; Gomes \& Nascimento, 2006). E como nos lembra Gomes (2003):

... o nosso propósito não é caminhar na direção oposta de se pensar a relação, privilegiando um gênero em detrimento de outro. Acreditamos que são igualmente válidos os posicionamentos que enfocam a saúde da mulher e a saúde do homem, desde que tais posicionamentos não percam a perspectiva relacional entre os gêneros e não se distanciem da promoção de saúde voltada para as necessidades humanas em geral (p. 826).

1 Este artigo descreve uma pesquisa de iniciação científica realizada no ano de 2006 pelo primeiro autor, sob orientação da segunda autora.

2 Endereço para correspondência: Departamento de Psicologia, UNESP/ Bauru. Av. Eng ${ }^{\circ}$ Luiz Edmundo Carrijo Coube, 14-01, Vargem Limpa. Bauru, SP. CEP 170333-360. E-mail: aclaudia@fc.unesp.br.
A sexualidade é um conceito amplo que envolve concepções históricas e culturais (Chauí, 1985; Maia, 2001; Nunes, 1987). Compreendendo a noção de gênero do mesmo modo, autores como Connell (1995), Navarro (2005), Maia (2008), Mead (2000), Unbehanum (2003) e Whitaker (1995) defendem que as características do masculino e do feminino são marcadas pelo contexto social e cultural em que foram concebidas; o gênero revela-se por meio de práticas produzidas e moldadas nas interações dos sujeitos em seu ambiente e contexto cultural.

Assim, a masculinidade não é determinada exclusivamente pelo aspecto biológico, mas também pelos aspectos psicológicos, educacionais e sociais (Connell, 1995; Negreiros \& Féres-Carneiro, 2004; Rogers \& Rogers, 2001; Silva, 2000). Além disso, a compreensão cultural sobre o masculino define um modelo de masculinidade predominante, incluindo padrões e normas a serem seguidas pelos homens em suas interações sociais (Connell, 1995; Negreiros \& Féres-Carneiro, 2004; Nolasco, 1993; Unbehanum, 2003). Segundo Connell, diferentes expressões do masculino são explicitadas num mesmo contexto social. Um conjunto dessas expressões representa um modelo hegemônico e estereotipado de masculinidade que revela e mantém características comportamentais em torno da posição dos homens na estrutura das relações de gênero. Por exemplo, maior atividade, desempenho, resistência e independência de homens em 
relação às mulheres. As características não enquadradas nesse padrão são, em geral, avaliadas negativamente entre os membros de nossa sociedade, uma vez que podem ser consideradas não-masculinas, tipicamente femininas ou relativas a homossexuais efeminados.

As prescrições acerca do que é ser homem e, portanto, do masculino, não determinam somente os comportamentos interpessoais a serem adotados e esperados socialmente, mas também influenciam na forma como homens percebem e lidam com seus corpos (Connell, 1995; Courtenay, 2000; Doyal, 2001; Gomes, 2003; Korin, 2001; Negreiros \& FéresCarneiro, 2004; Unbehanum, 2003). Na nossa sociedade, o corpo masculino ainda é visto como um corpo resistente que enfrenta qualquer dificuldade, um corpo viril necessário à competência para o trabalho e à manutenção da família e da prole (Connell, 1995; Gomes, Nascimento \& Araújo, 2007).

Nesse cenário, a necessidade em cuidar da saúde revelase como uma demanda predominantemente feminina que se distancia do cotidiano masculino, especialmente quando são considerados homens de menor poder aquisitivo e que não sofrem de doenças crônicas (Travassos, Viacava, Pinheiro \& Brito, 2002; Verbrugge, 1989). Como sinônimo de potência, desempenho e invulnerabilidade, o corpo masculino não requer cuidado, uma vez que é erroneamente visto como resguardado de possíveis problemas orgânicos ou psicológicos (Connell, 1995; Courtnay, 2000; Doyal, 2001; Korin, 2001; Gomes, 2003).

O distanciamento masculino referente aos cuidados com a saúde, principalmente em relação aos aspectos preventivos, à adesão ao tratamento e ao engajamento em situações de risco, atua negativamente sobre os índices de mortalidade masculina (Courtenay, 2000; Doyal, 2001; Gawryszewski, Koizumi \& Mello-Jorge, 2004; Macintyre, Hunt \& Sweeting, 1996; Verbrugge, 1982). Segundo Gawryszewski e cols., o risco de um homem se envolver em um evento fatal, sendo este intencional ou não, é maior que o da mulher. Comportamentos tidos como violentos e danosos, tais como o homicídio e suicídio, também ocorrem mais frequentemente entre os homens, aumentando entre eles a incidência de mortes ou de hospitalizações.

$\mathrm{Na}$ população brasileira, os dados oficiais em 2006 do Sistema de Informações de Mortalidade (SIM), indicaram um elevado coeficiente de mortes masculinas por causas externas - 107 mortes de homens por 100 mil habitantes - e um número significativamente menor no caso de mulheres - 21,8 mortes por 100 mil habitantes (Brasil/Ministério da Saúde (2006). Gawryszewski e cols. (2004) sugerem que essa frequência também pode estar relacionada com acidentes ocorridos no ambiente de trabalho.

De modo geral, as mulheres utilizam mais os serviços de saúde de maneira preventiva e, por isso, há uma situação de saúde desfavorável quando se trata do grupo masculino em relação ao feminino. As mulheres também apresentam mais doenças crônicas do que os homens, porém tais acometimentos são menos severos. Os homens têm uma expectativa de vida ao nascer sempre menor quando comparada à das mulheres, e taxas de mortalidade por faixa etária apontam uma maior mortalidade masculina em todos os grupos etários
(Bird \& Rieker, 1999; Macintyre \& cols., 1996; Macintyre, Ford \& Hunt, 1999; Pinheiro, Viacava, Travassos \& Brito, 2002; Verbrugge, 1982, 1989).

O diferencial de mortalidade e morbidade entre os gêneros explica-se, em parte, pelas variações no perfil de necessidades de saúde entre os gêneros, incluindo-se as demandas associadas à gravidez, ao parto e a certas características fisiológicas (Verbrugge, 1982; 1989). No entanto, esse diferencial não pode ser analisado unicamente pelo viés biológico, pois os fatores que influenciam a saúde masculina e feminina estão ligados entre si e atuam de forma multideterminada (Connell, 1995; Doyal, 2001; Gomes, 2003; Korin, 2001, Rogers \& Rogers, 2001). A relação entre gênero e saúde/adoecimento está tanto relacionada a fatores biológicos quanto a fatores psicológicos, sociais e culturais (Bird \& Rieker, 1999; Doyal 2001; Macintyre \& cols., 1996; Macintyre \& cols., 1999; Verbrugge, 1982, 1989). Segundo Pinheiro e cols. (2002) e Rabasquinho e Pereira (2007), as mulheres adoeceriam devido a fatores como o stress e sintomas depressivos, enquanto que os homens adoeceriam, ao longo prazo, em decorrência de fatores como pressões no trabalho e uso de drogas (e.g., álcool e cigarro).

Pesquisas no Brasil demonstram que há um número maior de homens internados em situação grave, e em geral, os homens vivem menos que as mulheres e morrem em maior quantidade (Figueiredo, 2005; Pinheiro \& cols., 2002). De acordo com o Suplemento Saúde da Pesquisa Nacional por Amostra de Domicílios, no nosso país, aproximadamente $23,5 \%$ das mulheres, em comparação a $18,2 \%$ dos homens, auto-avaliaram seu estado de saúde como 'regular', 'ruim' ou 'muito ruim'; 7\% entre as mulheres, e $5,6 \%$ entre os homens, referem-se a uma atual restrição de atividades rotineiras por motivo de saúde (Brasil/Ministério da Saúde, 2004). Essas estatísticas são consistentes com os relatos de alguns estudos, os quais apontam que, embora vivam mais, as mulheres tendem a reportar mais morbidade e problemas psicológicos que os homens (Macintyre \& cols., 1996; Macintyre \& cols., 1999; Verbrugge, 1982; 1989). Connell (1995), Courtenay (2000), Gomes (2003), Korin (2001) e Macintyre e cols.(1999) sugerem que homens são menos propensos a reportar problemas de saúde ao seu grupo de apoio e aos profissionais da saúde. As possíveis dificuldades dos homens em verbalizar as próprias fragilidades em relação à sua saúde representam o temor que eles têm em demonstrar fraqueza ou feminilidade perante os outros (Korin, 2001; Macintyre \& cols., 1999).

Determinados comportamentos de homens no que diz respeito à saúde corporal estão relacionados ao modelo de masculinidade; daí a negação, omissão ou ocultação sobre as necessidades de cuidados em saúde e consequente diminuição de procura por assistências médicas (Connell, 1995; Courtenay, 2000; Figueiredo, 2005; Korin, 2001; Unbehanum, 2003). Homens preferem utilizar serviços de saúde como farmácias ou prontos socorros, ainda que tais serviços sejam limitados às demandas emergenciais; nesses locais os homens seriam atendidos mais rapidamente e poderiam revelar, de forma breve e superficial, seus problemas de saúde (Braz, 2005; Figueiredo, 2005). Podemos considerar que o padrão masculino seja um indício de pouca procura por assistência 
médica e por cuidados preventivos em relação à saúde. Entretanto, também devemos lembrar que há escassos programas preventivos de saúde dirigidos aos homens (Braz, 2005; Figueiredo, 2005; Pinheiro \& cols., 2002). Para Figueiredo (2005), a saúde masculina envolveria três dimensões: (1) as histórias anteriores de aprendizagem dos homens; (2) o modo como os serviços se organizam para atender as peculiaridades masculinas; e, ainda, (3) o vínculo estabelecido entre os homens e os serviços de saúde.

A pesquisa no campo da saúde coletiva tem diversificado o interesse de suas investigações, procurando compreender as diferentes dimensões relativas à promoção da saúde. Alguns estudos relacionam a educação, cultura e o adoecimento (Connell 1995; Courtenay, 2000; Figueiredo, 2005; Gomes \& cols., 2007; Korin, 2001; Pinheiro \& cols., 2002; Unbehanum, 2003) e outros investigam os comportamentos necessários para a prevenção ou para a adesão ao tratamento, nas condições pessoais e ambientais existentes (Kerbauy, 2002; Matarazzo, 1980; Ribeiro, 2004). Recentemente, como ressaltam Gomes e Nascimento (2006) e Aquino (2006), há estudos que procuram investigar e discutir as especificidades do adoecer masculino, isto é, relacionar o gênero masculino às questões da saúde.

Matarazzo (1980) assegura que a "saúde comportamental" é um campo para o qual a Psicologia está qualificada a contribuir, principalmente se considerarmos o fato da Psicologia ser uma das mais destacáveis áreas da ciência que estuda o comportamento humano. No entanto, segundo Aquino (2006), apenas 11,4\% dos grupos brasileiros de pesquisa sobre Gênero e Saúde se enquadram dentro da área da Psicologia e, em grande parte, ainda estão focados somente em questões atuais da saúde feminina. A Psicologia da Saúde, como uma área interdisciplinar, deve estudar a relação entre comportamento e saúde, sem perder de vista os aspectos culturais nos quais estão inseridos os sujeitos que se comportam, sejam eles homens ou mulheres (Matarazzo, 1980; Ribeiro, 2004; Rogers \& Rogers, 2001).

Segundo Figueiredo (2005), muitas doenças podem ser evitadas ou controladas por comportamentos preventivos. Certos problemas de saúde não se manifestam de forma imediata, muitos podem ser evitados, e, nesse sentido, programas de ações preventivas poderiam intervir para a promoção e manutenção da saúde masculina e feminina. Os resultados de pesquisas nessa área têm contribuído tanto para manutenção da saúde, quanto para a prevenção de possíveis problemas físicos e psicológicos por meio de intervenções educacionais e institucionais (Gomes \& Nascimento, 2006).

Parece claro que os valores próprios da cultura masculina refletem entre os homens maior noção de invulnerabilidade, levando esses indivíduos a emitirem comportamentos de risco e poucas práticas preventivas. As pesquisas sobre masculinidade e saúde têm gerado debates por parte dos pesquisadores da área, todavia são escassos os estudos empíricos que procuram compreender a relação entre gênero e saúde/ adoecimento, descrevendo como é a concepção dos homens adoecidos quanto à sua saúde e à promoção desta.

Há estudos recentes sobre homens que procuram serviços de saúde (Gomes \& cols. 2007), mas não quando já estão doentes. A revisão da literatura indica que seria importante investigar como homens, que estejam vivenciando problemas de saúde em situação de hospitalização, compreendem a relação entre o gênero e os cuidados com a saúde, principalmente se considerarmos essa hospitalização o resultado da falta de engajamento em práticas preventivas e cuidados em saúde.

Nesse sentido, esta pesquisa, caracterizada como qualitativa-descritiva (Campos, 2000; Cozby, 2001/2003; Spata, 2003/2005), teve por objetivo investigar, a partir do relato de homens hospitalizados, as concepções sobre gênero e saúde/adoecimento, analisando a influência do modelo predominante masculino sobre as condições de saúde. Entendemos por concepções os pontos de vista, opiniões ou compreensões, decorrentes da história de aprendizagem de um indivíduo, sobre um determinado fenômeno. Partimos da hipótese de que os valores da cultura masculina envolveriam comportamentos de risco à saúde uma vez que afastam os homens de ações preventivas. E, no processo de adoecimento, os homens poderiam reconhecer se (e como) os padrões de gênero influenciaram seus comportamentos preventivos. Esses esclarecimentos podem contribuir para a área da Saúde, da Psicologia e da Educação, bem como, alertar para que as políticas públicas na área da saúde busquem estratégias e intensifiquem sua atenção à população masculina.

\section{Método}

\section{Participantes}

Participaram deste estudo dois homens adultos, H1 e H2 (com 57 e 47 anos, respectivamente), internados em um hospital do interior do estado de São Paulo, após terem sido submetidos a procedimento cirúrgico. Os dois participantes se encontravam em situação pós-operatória de cirurgia corretiva nas articulações: tendão do membro superior (H1) e ligamento do membro inferior (H2). Nos dois casos, os procedimentos cirúrgicos foram necessários devido ao fato de os participantes não terem seguido as devidas prescrições que preveniriam o agravamento do quadro clínico.

Os critérios para inclusão dos participantes foram: (a) ser adulto e do sexo masculino; (b) ser paciente internado no hospital em unidades de tratamento cirúrgico; (c) ter a cirurgia como uma recomendação médica, a partir de um quadro clínico agravado pela falta de prevenção, isto é, uma situação que poderia ser evitada; (d) não apresentar dor crônica no período pós-operatório. No período de 30 dias, apenas dois pacientes corresponderam a esses critérios de inclusão.

Os participantes foram previamente informados sobre as finalidades e procedimentos da pesquisa, e ambos concordaram e assinaram um termo de consentimento informado e voluntário de participação. Tais cuidados visaram preservar o exercício da autodeterminação dos participantes, adotando as melhores providências éticas na pesquisa. A realização desta pesquisa teve anuência do hospital e recebeu parecer favorável da Comissão de Ética local. 


\section{Material e instrumento}

Foram utilizados materiais como $C D s$ para gravação em áudio, um gravador digital portátil e também um roteiro de entrevista. O roteiro de entrevista foi elaborado pelos pesquisadores. Questões pertinentes ao problema de pesquisa foram distribuídas em blocos temáticos: (a) concepção da doença em função do gênero; (b) comportamentos preventivos; (c) comportamentos em relação à doença e ao tratamento; e (d) consequências do adoecer. Em cada bloco temático, as questões foram elaboradas para investigar quais características os participantes atribuíam aos gêneros, bem como a origem desse ponto de vista (por exemplo, "Quem você acha que adoece mais, o homem ou a mulher?", "Como você chegou a essa conclusão?", “O que te levou a pensar desse modo"?). As concepções de gênero foram investigadas tanto em relação ao masculino, quanto ao feminino

Tal roteiro foi testado em sua funcionalidade, na situação piloto, em um homem adulto doente, embora o mesmo não estivesse em situação de internação hospitalar. Por questões éticas e por dificuldade em encontrar participantes que atendessem aos critérios de seleção, optou-se por realizar o estudo piloto em situação não exatamente igual à da coleta de dados. O roteiro sofreu pequenas alterações na ordem e no agrupamento das questões, bem como a inclusão de outras ao final.

\section{Procedimento}

Devido às peculiaridades do ambiente hospitalar, o controle absoluto de interferências fica prejudicado. Tentando minimizar tal dificuldade, as entrevistas foram efetuadas em horários nos quais as visitas ao leito, por parte da equipe técnica e médica, ocorriam com menor frequência. Cada entrevista foi realizada diante do leito hospitalar, com a devida privacidade, garantindo-se o mínimo de interferências possíveis. Procurando garantir condições mínimas de rapport, o pesquisador se dirigia e se apresentava ao paciente, dialogando livremente com ele. Após isso, o estudo e seus objetivos, bem como os procedimentos de coleta foram apresentados de forma a esclarecer o paciente e a convidálo a participar da pesquisa. Somente após esse diálogo e a assinatura do termo de consentimento, no qual o participante concordava em participar como voluntário na pesquisa, é que se iniciava a coleta de dados propriamente dita. Antes da gravação da interação verbal, o pesquisador registrava em protocolo próprio a identificação do paciente e dados gerais da situação da entrevista (data, horário e local).

\section{Análise de dados}

O tratamento de dados foi baseado no método da análise de conteúdo, tal como descreveu Bardin (1979) e, mais recentemente, Franco (2005). Toda a interação verbal da entrevista foi registrada por áudio-gravação e transcrita, na íntegra, para leitura e pré-análise. Tal como prevê a análise de conteúdo, as unidades foram agrupadas por temas e, em seguida, configuradas em categorias, tendo como parâmetro questões de gênero.

Os relatos foram analisados e organizados em três agrupamentos temáticos. O primeiro agrupamento "Comportamentos preventivos em saúde" reuniu os relatos que se referiram a explicações, justificativas e argumentos sobre como homens e mulheres cuidam e se preocupam com a sua saúde. O agrupamento "Saúde e Adoecimento" dizia respeito ao modo como eles percebiam a possível ocorrência de doenças em homens e mulheres. Finalmente, o terceiro agrupamento de respostas, "Comportamentos diante da doença", agrupou conteúdos sobre a forma de homens e mulheres lidarem com o adoecimento.

\section{Resultados}

\section{Comportamentos preventivos em saúde}

Neste agrupamento, podemos conhecer a percepção dos homens entrevistados sobre os cuidados com a saúde de homens e de mulheres. Para eles, as mulheres se preocupariam e cuidariam mais da saúde, por diferentes motivos: porque devem cuidar das questões obstétricas e ginecológicas, porque têm mais acesso a informações sobre doenças e atitudes preventivas, ou ainda, porque se preocupam com questões de estética. Os homens se preocupariam e cuidariam menos da saúde porque têm preocupações com o trabalho e evitam se ausentar dele e, ainda, porque teriam dificuldades diante da realização de alguns exames, refletindo preconceitos sociais.

\section{Concepção de que as mulheres se preocupam e cuidam mais da sua saúde do que os homens}

Para os homens entrevistados, as mulheres se preocupariam mais com a saúde do que homens por diferentes razões: pela natureza de seu corpo biológico reprodutivo que requer cuidados frequentes; porque mulheres têm mais informações disponíveis sobre saúde; porque mulheres são mais preocupadas com a estética; porque são mais "inteligentes" quando se trata de cuidar da saúde. Por outro lado, os homens se preocupariam menos em cuidar da sua saúde por questões concernentes ao preconceito e, ainda, por questões relacionadas ao trabalho.

Mulheres cuidam mais da saúde devido a questões obstétricas e ginecológicas. Um forte argumento dos homens para justificar o fato das mulheres cuidarem mais da sua saúde foi a questão ginecológica e reprodutiva, como diz H2: "ela tem o útero, tem filhos e hormônios". Um outro relato esclarece:

... tudo gerado principalmente na parte reprodutiva dela, a parte hormonal dela. ... Olha, pra você ver, a minha mulher, ela faz Papanicolau todo ano, mamografia todo ano e depois de uma certa idade aparecem outros problemas. O nivel hormonal que ela está tratando $(\mathrm{H} 1)$. 
Segundo os homens entrevistados, as mulheres teriam mais comportamentos preventivos e de autocuidado do que os homens uma vez que a mulher deveria realizar consultas médicas e exames diversos com mais frequência e de maneira rotineira, pela condição corporal e funcional do corpo feminino. É interessante destacar que, para um dos homens, as razões que fazem a mulher ter mais comportamentos preventivos com a saúde seriam as preocupações com o aparelho reprodutor: "a mulher só tem essa coisa de mais médica porque tem que cuidar de toda aquela parte feminina dela" (H1). Não ter essa preocupação seria algo vantajoso aos homens: "e isso é uma coisa que o homem não tem, por sorte" (H1).

Mulheres cuidam mais da saúde porque têm mais informações disponíveis. Um outro motivo comentado foi o interesse das mulheres por informações sobre saúde. O Participante $\mathrm{H} 1$ chega a dizer que as mulheres "são mais prevenidas e se interessam mais, elas buscam mais informação". Há também o argumento de que elas procurariam mais o serviço de saúde em decorrência de maior difusão de programas televisivos que informam sobre saúde feminina. Por um lado, é interessante lembrar que atualmente tanto homens quanto mulheres da classe média teriam acesso a meios de comunicação e aos programas informativos sobre o tema, porém, nos parece verdadeiro que há uma maior veiculação de programas que abordem somente a questão da saúde feminina.

... você pode ver nesses programas femininos que a gente vê na televisão, a quantidade de informação que existe sobre saúde da mulher é violenta, é uma quantidade muito grande e elas se interessam, e agora, você não vê programa de homem falando da saúde de homem. Você vê mulher falando da saúde de homem na televisão. Não tem programa de homem porque o homem não se interessa (H1).

Mulheres cuidam mais da saúde porque se preocupam com a estética. Para o Participante $\mathrm{H} 2$, a preocupação de mulheres com a estética corporal as faz "tentar resolver até mais rápido que o homem essa coisa com a saúde", embora ele ressalte que, atualmente, há homens também preocupados com a estética que passaram a se preocupar mais com a saúde.

Homens cuidam menos da saúde por questões de preconceito e as mulheres seriam mais inteligentes por não se comportarem assim. Quando se pensa em prevenção entre os homens, o exame lembrado foi o de próstata e, ainda assim, remetido a uma dificuldade relacionada ao preconceito atribuído a esse exame. Isso porque, devido ao procedimento de um dos exames ser o toque anal, muitos homens evitam a sua realização.

O homem, por preconceito único, a única manutenção que ele faz é o exame de próstata e por um grande preconceito a grande maioria ainda não faz preventivamente e ele só faz quando a coisa fica preta pro lado dele. Ai ele corre! Então a mulher é muito mais inteligente, muito mais sensata, ela se cuida mais, mais é por pura inteligência. A mulher é muito mais inteligente que o homem nessa parte (H1).
Homens cuidam menos da saúde por questões relacionadas ao trabalho. Um dos homens entrevistados ressaltou a dificuldade em cuidar da saúde devido às questões do trabalho. Pareceu-nos importante perceber que a jornada de trabalho em horas diárias, para muitos homens, implicaria em dificuldades para que eles procurassem ajuda médica, especialmente preventivamente. Para os participantes, as consultas médicas e os exames podem comprometer o trabalho, isto é, gerar ausências, faltas e, portanto, afastá-los dos compromissos sociais e econômicos. Se há uma preocupação com a sobrevivência econômica atual e futura, a manutenção do emprego e da renda parece ser mais importante do que a manutenção da saúde.

\begin{abstract}
O homem já fica preocupado por causa do serviço, o que o patrão vai dizer se ele ficar em casa. ... Você não pode deixar o patrão perceber que você não faz falta que senão ele pode te mandar embora. ..., ele fica mais estressado, ele quer voltar logo pra ativa, tem tanta disputa profissional. ... O mundo de hoje não dá chance para uma pessoa não estar empregada. ... ele já tem preocupação com o futuro e de deixar alguma coisa com os filhos e por isso ele não é uma pessoa de se tratar tanto. Tomou um comprimido e parou de doer está bom. Ele vai cuidar mesmo quando não há o que fazer (H1).
\end{abstract}

\section{Saúde e adoecimento}

Neste agrupamento, podemos conhecer a percepção dos homens entrevistados sobre a relação entre doença e saúde de homens e mulheres. Para eles, em muitas ocasiões as mulheres e os homens ficariam igualmente doentes; no entanto, os homens procurariam por ajuda médica em situações drásticas e, ao adoecerem, revelariam um estado mais severo de saúde.

\section{Concepção de que mulheres e homens ficam doentes igualmente}

É interessante observar que, para esses homens, mesmo que as mulheres procurem cuidar mais da sua saúde, ela não estaria livre de doenças, principalmente as não relacionadas ao aparelho genital reprodutivo. Para um dos homens, mesmo a mulher se prevenindo mais, a ocorrência de doenças seria proporcional entre homens e mulheres. Por exemplo, quando se trata de doenças crônicas não relacionadas às questões ginecológicas e obstétricas, como a diabetes ou doenças cardíacas (H1). Para o outro (H2), a mulher sofreria mais de doenças devido a sua "natureza estressada". Os relatos sugerem que problemas de saúde são mais evidentes entre as mulheres, mas isso não significaria que elas ficariam "menos ou mais doentes" do que os homens, conforme exemplificado a seguir:

\footnotetext{
Eu acho que a coisa está bem equilibrada viu. Eu acho que é igual, não tem diferença, mais um que o outro. ... Mas em termos de doença mesmo, eu acho que a coisa fica igual. ... doente quando eu falo é diabetes, é uma assim doença de coração, uma safena, uma trombose, sei lá. Esse monte de doença, aí você pode ver que você não vê mais em um do que no outro (H1).
} 
... diferente do homem que ainda joga uma bola, pratica um esporte, eu acho que a mulher é um pouco mais assim estressada e por isso ela sofre um pouco mais (H2).

\section{Homens adoecem de forma mais severa e só procuram por ajuda médica diante de situações emergenciais e críticas e não de modo preventivo, como fazem as mulheres}

Para os participantes, a falta de prevenção em relação à saúde poderia favorecer a ocorrência da doença ou agravar a sua manifestação. Segundo eles, o adoecimento masculino é mais severo, o que não aconteceria no caso das mulheres devido aos cuidados preventivos mais frequentes.

No caso do homem, ele negligencia o exame da próstata, aquele exame anal ... ele vai recorrer a coisa está grave, ele já tem que retirar, fazer a extração porque já está com câncer. Se ele fosse fazer aquela prevenção, como a mulher geralmente faz, ele teria previsto isso há muito mais tempo e não precisasse fazer uma cirurgia tão radical, fizesse um tratamento. Talvez não chegasse a ter, porque é justamente pra isso que serve o exame $(\mathrm{H} 1)$.

Os participantes evidenciam que os homens ficam mais doentes porque são mais negligentes com os cuidados com a sua saúde e não se comportam de modo preventivo, adiando ao máximo a procura por ajuda médica, o que agrava sua condição. Para eles, as mulheres procuram auxílio médico preventivamente, isto é, antes da manifestação da doença, o que seria diferente entre os homens. Segundo os relatos, homens procuram auxílio médico quando os problemas são evidentes. Diante de dificuldades ou de uma situação "grave", a procura pelo médico torna-se necessária e inevitável.

Olha, eu vou dizer por mim, eu fui procurar o urologista quando eu comecei a sentir assim uma certa dificuldade para urinar ..., uma coisa que poderia levar um ou dois minutos leva três porque o jato fica fraco ... Durante a noite você levanta pra urinar diversas vezes, então, começa a incomodar, ai eu procurei, mas se não tivesse dado problema eu não teria procurado. A mulher, ela vai espontaneamente (H1).

Homem só vai se cuidar em último caso, só quando o problema é muito sério. Existe um medo até de falar! Assim: "ah, eu não vou no médico para não aparecer problema". ... Ele só vai ver quando a coisa fica muito feia pro lado dele ou quando a mulher obriga ..., só vai se ele for forçado de uma forma ou de outra. Ou se a doença vem ou se a mulher obriga (H1).

Os homens entrevistados, em situação de hospitalização, relacionaram a manifestação da sua doença e da necessidade da cirurgia aos seus comportamentos não preventivos. Além disso, a "situação crítica", relatada por um deles como o fato que o fez procurar ajuda médica, sugere um desconforto pessoal físico relacionado ao próprio corpo que afeta a sua vaidade. Exemplo:

... eu [procurei tratamento médico quando] senti falta de uma condição física boa, como a que eu tinha, foi o que eu mais senti porque eu sempre tive uma condição fisica boa. Não poder praticar esporte de uma forma legal foi ruim, teve consequências: meu colesterol aumentou e triglicéris. Por isso eu estou me cuidando, eu também sou um pouco vaidoso $(\mathrm{H} 2)$.

\section{Comportamentos diante da doença}

Este agrupamento refere-se à percepção dos homens entrevistados sobre como homens e mulheres se comportariam quando adoentados. Para eles, as mulheres seriam mais otimistas quanto à cura da doença e teriam melhores condições de aderir ao tratamento médico do que os homens.

\section{Concepção de que as mulheres seriam mais otimistas e teriam melhores condições emocionais para lidar com a doença}

Para os homens entrevistados, as mulheres teriam condições vantajosas para lidar com o tratamento de uma doença, uma vez que, diante da ocorrência do adoecimento, seriam mais otimistas e corajosas e também seriam mais práticas, cuidadosas e responsáveis na adesão ao tratamento. A mulher tenderia a ter uma atitude mais objetiva no que concerne à resolução do problema.

A ideia sugerida é que, uma vez doentes, as mulheres teriam melhores condições emocionais em aceitar o diagnóstico e aderir ao tratamento, comportamento que poderia ter sido aprendido desde a infância. Por outro lado, os homens teriam maior dificuldade em fazer o mesmo devido à sua natureza. Em ambos, questões de gênero são lembradas para justificar comportamentos para o enfrentamento de doenças.

A mulher, nessa parte, ela é muito objetiva ... ela vai prá resolver a coisa e ficar boa logo, ela pensa em resolver o problema dela logo. ... A mulher pensa por esse lado, ela é mais prática e mais corajosa e não tem preconceito. Eu não sei se é porque ela, já desde criança, tem a mãe fazendo esses exames todos $e$, então, ela não tem preconceito. A mulher, nesse sentido, ela é mais objetiva e mais responsável (H1).

A mulher, na realidade, ela pensa que vai ficar bem porque ela é mais forte do que o homem nesse ponto, ela é mais cuidadosa, vai fazer a coisa conforme o médico passa para ela.... A mulher pensa mais positivo que os homens. O homem fica falando: "ah, eu estou doente, não estou bom". A maioria ... porque tem o instinto masculino quando ele passa por isso. Acho que o homem quando nasce já desvia para essa forma, ele faz assim quando fica doente. É o que eu vejo os homens fazerem quando ficam doentes (H2).

Diante do adoecimento, o participante $\mathrm{H} 1 \mathrm{diz}$ aderir às recomendações médicas: “... o médico chegou na conclusão da cirurgia e eu vim e fiz. Agora eu estou me recuperando, mas eu fiz o que tinha que fazer". Todavia, o relato sugere também que a mediação feminina foi fundamental para que ele se submetesse aos cuidados prescritos e que sem o apoio da mulher o tratamento seria inviável: 
Não, isso dai com o tempo e em convivência com a mulher, né! Então ela vai vendo e tendo essas sacadas de informação e vai te explicando e você vai aprendendo. ... Eu tenho que ficar imóvel, então, se eu não tiver o apoio dela, talvez eu nem tivesse feito a cirurgia se eu não tivesse o apoio que eu tenho dela (H1).

\section{Discussão}

Os resultados obtidos no presente estudo mostram que, no discurso masculino, quando se trata de doenças crônicas não relacionadas às questões reprodutoras, há a compreensão de que homens e mulheres ficam, em relação à frequência, igualmente doentes. Entretanto, as mulheres procuram mais por atendimentos médicos, prevenindo-se e engajando-se mais em cuidados com a saúde do que os homens, corroborando estudos de Bird e Rieker (1999), Doyal (2001) e Pinheiro e cols. (2002) Um forte argumento aqui relatado, e também encontrado na literatura (Martins, 2004; Rohden, 2003), é que as mulheres se preocupam mais com a saúde do que os homens em função de sua "natureza biológica" (características relacionadas à reprodução). Muitos comportamentos considerados femininos na nossa sociedade sugerem que elas teriam maior cuidado com o corpo e com a prole, o que pode justificar a ideia de que as mulheres se preocupariam com saúde preventiva em decorrência da concepção, gravidez e parto. A natureza inata de homens e mulheres pode influenciar os comportamentos emitidos com relação à saúde, mas quando se trata de gênero, é difícil separar as características biológicas do contexto social em que foram produzidas, principalmente se for considerado que a construção de gênero é um fenômeno cultural (Connell, 1995; Maia, 2008; Navarro, 2005; Whitaker, 1995).

Ainda que questões fisiológicas possam influenciar a necessidade de cuidados por parte das mulheres, elas não são as únicas variáveis determinantes da diferença em procurar cuidados médicos. Doyal (2001) e Martins (2004) sugerem que esse diferencial é fundamentado pelo senso comum, no qual a mulher equivocadamente se encaixa em perfis de fragilidade, e isso pode ser generalizado até mesmo sobre o corpo, o que parece contribuir para a medicalização e maior procura por serviços de saúde por parte das mulheres. Tais fatores são oriundos da educação diferenciada que mulheres recebem no que se refere ao monitoramento de sua saúde reprodutiva (Martins, 2004; Rohden, 2003). A maior aproximação das mulheres com os cuidados em saúde também se estabelece diante de valores culturais e históricos que incentivam certas características femininas, como relatar as próprias fragilidades físicas e emocionais (Doyal, 2001; Martins, 2004; Rohden, 2003), o que não aconteceria no caso dos homens, que recebendo uma educação calcada nos valores de masculinidade, não aprendem a reconhecer, nem relatar, uma condição que exponha fragilidades, como observamos nos relatos obtidos. O modelo social masculino aprendido e incorporado pelas pessoas, como afirmam Braz (2005) e Gomes e cols. (2007), exerce uma influência negativa sobre o autocuidado de homens.

Uma outra justificativa para que os homens cuidem menos de sua saúde diz respeito ao mundo do trabalho. A preocupação em ser o responsável por prover a família diante de uma sociedade desigual economicamente indica que se manter ativo e produtivo nesta sociedade tem um alto preço, inclusive de autodestruição. Rabasquinho e Pereira (2007) lembram os altos índices de adoecimento masculino em decorrência do uso de drogas e ou problemas no trabalho.

Os relatos dos homens também apontam que, socialmente, as mulheres teriam melhores condições para assumir os cuidados com a saúde: assistem mais à televisão e se interessam mais sobre saúde, bem como disponibilizam mais tempo para procurar serviços de saúde e realizar exames preventivos, talvez considerando aqui o trabalho doméstico como um trabalho que requer menos empenho pessoal. De qualquer forma, esses comportamentos em relação à saúde têm relação direta com a concepção social de gênero e são determinantes na reprodução de certas práticas culturais respaldadas em valores e regras sexistas (Connell, 1995; Courtenay, 2000; Doyal, 2001).

A propósito da televisão, um dos participantes identificou que, nos programas televisivos, existe uma maior propagação de informações sobre saúde das mulheres, reconhecendo o déficit de informações específicas para os homens. Assim como as políticas públicas, outras instâncias sociais, tal como a indústria cultural, mantêm longe as questões sobre saúde masculina, inclusive pelo fato deste debate não ser valorizado por esse público específico.

Também ficou evidente que, para os participantes, as mulheres assumem em maior grau atitudes preventivas de cuidados com a saúde, lidam melhor com o enfrentamento do diagnóstico e a adesão ao tratamento. Segundo os relatos, os homens se previnem menos e evitam as orientações médicas quando ainda não estão acometidos severamente. Destaca-se, no caso dos depoentes, que esta procura somente ocorreu na presença de sintomas graves, já estando comprometidas suas funções econômicas e sociais. A procura por tratamento médico tornou-se prioridade apenas quando os sintomas determinaram restrições físicas, laborais ou prazerosas, fato também descrito nos estudos de Braz (2005), Courtenay (2000); Figueiredo (2005), Gomes (2003) e Pinheiro e cols., (2002) ou, ainda, quando os limites impostos pela doença sinalizaram possíveis consequências mais aversivas quando comparadas à possibilidade de se sentir frágil ou improdutivo.

O fato de homens postergarem ao máximo a procura por ajuda médica, alegando dificuldades diante da possibilidade de perda do emprego, da necessidade de estar ativo e de demonstrar resistência, se revela nas situações em que eles desprezam o reconhecimento dos primeiros sintomas de uma possível doença ou quando não seguem as recomendações médicas; isso ocorreu enquanto os limites nas atividades cotidianas não apareceram e eles acreditavam controlar a sua saúde. Ao desvalorizar o autocuidado e adiar a procura por assistência médica e preventiva, o homem aumenta os riscos de sofrer danos mais fatais e isto se reflete no fato de os homens serem alvo de problemas de alta letalidade (Bird \& Rieker, 1999; Doyal, 2001; Pinheiro \& cols., 2002).

Mesmo quando os homens assumem os cuidados com sua saúde, seja pelas razões limitantes de sua vida social e econômica ou mesmo pelas preocupações com o caráter funcional do corpo, o padrão de masculinidade ainda parece ser determinante, uma vez que esses cuidados visam manter 
o status de virilidade, força e desempenho social (Connell, 1995; Nolasco, 1993). No caso dos entrevistados, uma das razões da procura por assistência médica foi a possibilidade de perder agilidade e eficiência, ou seja, o risco de não corresponder aos valores prescritos pelo padrão social do gênero masculino, como também apontam Connell (1995), Coutenay (2000), Korin (2001), Nolasco (1993) e Unbehanum (2003). Outro motivo se deu pelo fato desses homens serem casados e terem atribuído à esposa o papel de mediar o efetivo cuidado com a saúde, o que só ocorreu após as significativas restrições físicas ocasionadas pelo agravamento das lesões e, portanto, após o reconhecimento do adoecimento.

Por fim, destaca-se que as concepções sobre a saúde/ doença por parte de homens já adoecidos parecem ser semelhantes àquelas encontradas na literatura consultada a partir dos discursos de homens saudáveis. Entretanto, fica evidente, para esses homens hospitalizados, o reconhecimento de que a falta de prevenção em relação à saúde favoreceu a ocorrência da doença ou agravou a sua manifestação. Além disso, diferentes consequências imediatas, como limites para trabalhar ou praticar esportes, é que sinalizaram a eles a necessidade em procurar ajuda médica e aceitar a prescrição da cirurgia. Nessa situação, a figura feminina, na voz das esposas foi significativa para o estabelecimento da relação homem/ cuidados com a saúde.

\section{Considerações Finais}

Os resultados deste estudo corroboram a literatura que aponta a existência de um modelo masculino desfavorável à manutenção da saúde dos homens, ressaltando a relevância sobre a investigação acerca da influência do gênero sobre os comportamentos relacionados à prevenção de doenças. Permeando o discurso dos homens, algumas características do modelo de masculinidade e feminilidade predominante em nossa cultura ficam sinalizadas pelas diferenças em relação aos cuidados com o corpo e com a saúde, tanto no que se refere aos comportamentos preventivos quanto aos de aceitação e adesão ao tratamento médico diante do adoecimento. Práticas culturais sobre o masculino afastam homens dos cuidados com sua saúde, o que parece ser percebido por eles diante de situações críticas em que o enfrentamento da doença torna-se inevitável.

Estes dados não são generalizáveis a toda população; novos estudos poderiam abarcar uma gama maior de participantes em diferentes situações que não o leito hospitalar, em diferentes fases do desenvolvimento humano - adolescência e/ou a idade avançada - ou ainda ouvir o relato de mulheres e de profissionais da saúde também sobre esse mesmo tema. A investigação sobre estilos de vida tipicamente masculinos e a sua influência sobre o autocuidado também parece algo relevante para a ampliação do conhecimento desta temática.

Existem comportamentos que geram problemas à saúde que parecem ser contingentes às características sócio-culturais de gênero, que poderiam ser abordados no âmbito dos serviços de saúde, atendendo, como afirmam Doyal (2001), Figueiredo (2005) e Gomes (2003), tanto a população feminina quanto masculina.
O esclarecimento das dificuldades de homens em cuidar da saúde, justificadas por padrões de comportamento rígidos, vinculados a um modelo social masculino, deveria incitar a políticas públicas sobre prevenção de saúde que, por um lado, ampliem as campanhas direcionadas à população masculina e, por outro, tenham por base reflexões advindas das especificidades de gênero identificadas como, por exemplo, os preconceitos, as crenças errôneas que relacionam a doença à fraqueza e/ou diminuição de virilidade ou ainda lidar com as questões sociais e econômicas subjacentes. A reflexão sobre as concepções apresentadas neste estudo pode favorecer ações educativas planejadas de modo específico para a demanda masculina, que contribuam para a redução de taxas de morbidade e mortalidade e sejam eficazes na promoção de saúde dessa população.

\section{Referências}

Aquino, E. M. L. (2006). Gênero e saúde: perfil e tendências da produção científica no Brasil. Revista de Saúde Pública, 40, 121-132.

Bardin, L. (1979). Análise de conteúdo. Lisboa: Edições 70.

Bird, C. E., \& Rieker, P. P. (1999). Gender matters: An integrated model for understanding men's and women's health. Social Science and Medicine, 48, 745-755.

Brasil/Ministério da Saúde (2004). Inquérito domiciliar sobre comportamentos de risco e morbidade referida de doenças e agravos não transmissíveis: Brasil, 15 capitais e Distrito Federal. Rio de Janeiro: Inca.

Brasil/Ministério da Saúde. DATASUS (2006). Informações de saúde. Retirado em 14/05/2006 de http://www.datasus.gov.br/ catalogo $/ \mathrm{sim} / \mathrm{htm}$.

Braz, M. (2005). A construção da subjetividade masculina e seu impacto sobre a saúde do homem: reflexão bioética sobre justiça distributiva. Ciência e Saúde Coletiva, 10, 97-140.

Campos, L. F. L. (2000). Métodos e técnicas de pesquisa em psicologia. Campinas: Alínea.

Chauí, M. (1985). Repressão sexual - essa nossa (des)conhecida. São Paulo: Brasiliense.

Connell, R. W. (1995). Políticas da masculinidade. Educação e Realidade, 20, 185-206.

Courtenay, W. H. (2000). Constructions of masculinity and their influence on men's well-being: A theory of gender and health. Social Science \& Medicine, 50, 1385-1401.

Cozby, P. C. (2003). Métodos de pesquisa em ciências do comportamento (P. I. C. Gomide \& E. Otta, Trads.). São Paulo: Atlas. (Trabalho original publicado em 2001)

Doyal, L. (2001). Sex, gender, and health: the need for a new approach. British Medical Journal, 323, 1061-1063.

Figueiredo, W. (2005). Assistência à saúde dos homens: um desafio para os serviços de atenção primária. Ciência \& Saúde Coletiva, 10, 105-109.

Franco, M. L. P. B. (2005). Análise de conteúdo (2a ed.). Brasília: Liber Livro.

Gawryszewski, V. P., Koizumi, M. S., \& Mello-Jorge, M. H. P. (2004). Causas externas no Brasil no ano de 2000: comparando a mortalidade e a morbidade. Cadernos de Saúde Pública, 20, 995-1003. 
Gomes, R. (2003). Sexualidade masculina e saúde do homem: proposta para uma discussão. Ciência \& Saúde Coletiva, 8, 825-829.

Gomes, R., Nascimento, E. F., \& Araújo, F. C. (2007). Por que os homens buscam menos os serviços de saúde do que as mulheres? As explicações de homens com baixa escolaridade e de homens com ensino superior. Cadernos de Saúde Pública, 23, 556-574.

Gomes, R., \& Nascimento E. F. (2006). A produção do conhecimento da saúde pública sobre a relação homem-saúde: uma revisão bibliográfica. Cadernos Saúde Pública, 22, 901-911.

Kerbauy, R. R. (2002). Comportamento e saúde: doenças e desafios. Psicologia USP, 13, 11-28.

Korin, D. (2001). Nuevas perspectivas de genero en salud. Adolescência Latinoamericana, 2, 67-79.

Macintyre, S., Ford, G., \& Hunt, K. (1999). Do women “overreport" morbidity? Men's and women's responses to structured prompting on a standard question on long standing illness. Social Science \& Medicine, 48, 89-98.

Macintyre, S., Hunt, K., \& Sweeting, H. (1996). Gender differences in health: Are things really as simple as they seem? Social Science \& Medicine, 42, 617-624.

Maia, A C. B. (2001). Sexualidade: reflexões sobre um conceito amplo. SBPN-Scientific Journal, 5, 45-48.

Maia, A. C. B. (2008). Sexualidade, deficiência e gênero: reflexões sobre padrões definidores de normalidade. Em R. D. Junqueira (Org.), Diversidade sexual e educação: problematizações sobre a homofobia nas escolas (Coleção Educação para Todos) (pp. 265-291). Brasília: Ministério da Educação, UNESCO.

Martins, A. P. V. (2004). Visões do feminino: a medicina da mulher nos séculos XIX e XX. Rio de Janeiro: Fio Cruz.

Matarazzo, J. D. (1980). Behavioral health and behavioral medicine: Frontiers for a new Health Psychology. American Psychologist, $35,807-817$.

Mead, M. (2000). Sexo e temperamento (4 $4^{\mathrm{a}}$ ed.). São Paulo: Perspectiva.

Navarro, C. Z. (2005). Questões de gênero no contexto escolar. Monografia de Conclusão de Curso, Universidade Estadual Paulista, Bauru.

Negreiros, T. C. G. M., \& Feres-Carneiro, T. (2004). Masculino e feminino na família contemporânea. Estudos e pesquisas em Psicologia, 4, 34-47.

Nolasco, S. A. (1993). O mito da masculinidade (2a ed.). Rio de Janeiro: Rocco.

Nunes, C. A. (1987). Desvendando a sexualidade. Campinas: Papirus.

Pinheiro, R.S., Viacava, F., Travassos, C., \& Brito, A. S. (2002). Gênero, morbidade, acesso e utilização de serviços de saúde no Brasil. Ciência \& Saúde Coletiva, 7, 105-109.
Rabasquinho, C., \& Pereira, H. (2007). Gênero e saúde mental: uma abordagem epidemiológica. Análise Psicológica, 25, 439-454.

Ribeiro, J. L. P. (2004). Avaliação das intenções comportamentais relacionadas com a promoção e protecção da saúde e com a prevenção das doenças. Análise Psicológica, 22, 387-397.

Rohden, F. (2003). A construção da diferença sexual na Medicina. Cadernos de Saúde Pública, 1 (2, Suplemento), 201- 212.

Rogers, W. S., \& Rogers, R. S. (2001). The psychology of gender and sexuality: An introduction. Philadelphia: Open University Press.

Silva, S. G. (2000). Masculinidade na história: a construção cultural da diferença entre os sexos. Psicologia Ciência e Profissão, 20, 8-15.

Spata, A. (2005). Métodos de pesquisa-ciência do comportamento e diversidade humana (A. B. Pinheiro de Lemos, Trad.). Rio de Janeiro: LTC. (Trabalho original publicado em 2003)

Teles, M. A. A. (1999). Breve histórico do feminismo no Brasil ( $1^{\mathrm{a}}$ ed.) São Paulo: Brasiliense.

Travassos, C., Viacava, F., Pinheiro, R., \& Brito, A. (2002). Utilização dos serviços de saúde no Brasil: gênero, características familiares e condição social. Revista Panamericana de Salud Pública, 11, 365-373.

Unbehaum, S. G. (2003). Gênero, masculinidade e prevenção. Em L. S. Jeolás \& A. Oliveira (Orgs.), Anais do seminário sobre cultura, saúde e doença (pp. 150-162). Londrina: Universidade Estadual de Londrina.

Verbrugge, L. M. (1989). The Twain Meet: Empirical explanations of sex differences in health and mortality. Journal of Health and Social Behavior, 30, 282-304.

Verbrugge, L. M. (1982). Sex differentials in health. Public Health Reports, 97, 417-437.

Whitaker, D. C. A. (1995). Menino - menina: sexo ou gênero? Em R. V. Serbino \& M. A. R. L. Grande, (Orgs.), A escola e seus alunos: o problema da diversidade cultural (pp. 31-52). São Paulo: Unesp. 